\title{
EL TESTAMENTO DE GREGORIO FERNÁNDEZ Y EL PROCESO DE CULMINACIÓN DEL RETABLO MAYOR DE LA CATEDRAL DE PLASENCIA (CÁCERES)
}

\author{
VicENTE MÉNDEZ HeRnÁN \\ Universidad de Extremadura
}

\begin{abstract}
El presente artículo da a conocer la fecha y parte del testamento de Gregorio Fernández, a tenor del traslado que existe del mismo en el Archivo catedralicio de Plasencia, y a raíz de la definitiva conclusión de su retablo mayor, del que se aportan nuevos datos.

Palabras clave: Gregorio Fernández; Escuela Vallisoletana; Siglo XVII; Testamento; Retablo; Catedral de Plasencia.

\section{GREGORIO FERNÁNDEZ'S WILL AND THE COMPLETION OF THE MAIN ALTARPIECE FOR PLASENCIA CATHEDRAL (CÁCERES)}

This article offers the date and part of the Testament of Gregorio Fernández, thanks to the extract located in the Plasencia Cathedral Archive, which was presented to the cathedral by the sculptor's heirs in order receive the payment due upon completion of the main altarpiece by the artist prior to his death.

Key words: Gregorio Fernández; Valladolid School; $17^{\text {th }}$ century; Testament; Altarpiece; Plasencia Cathedral.

Gregorio Fernández ( $†$ 1636) es quizás uno de los artistas españoles sobre los que disponemos de un mayor número de trabajos de investigación, dada su importancia para la evolución escultórica del siglo XVII y la intensa actividad que desarrolló. Desde la primera biografía que Antonio Palomino escribiera en 1724 sobre el "venerable" artista ${ }^{1}$, hasta la monografía más reciente, publicada a raíz de la última exposición retrospectiva celebrada en 1999 bajo la dirección de Jesús Urrea ${ }^{2}$, junto al importante trabajo que en 1980 nos ofreció el profesor Martín González sobre su trayectoria ${ }^{3}$, han sido numerosos los estudios que han permitido conocer cada vez mejor la figura de Gregorio Fernández y el entorno que le rodeó ${ }^{4}$, aunque lo cierto es que aún hoy existen -en palabras de J. Urrea- algunas lagunas en su biografía que serán difíciles o casi imposibles de rellenar ${ }^{5}$.

Una de esas lagunas atañe a la fecha concreta en la que otorgó testamento, así como a su contenido, que en parte conocemos -aunque no en lo más sustancial- por las referencias que en su momento publicaron Ceán Bermúdez y Martí y Monsó; el primero lo hizo valiéndose de la partida de defunción del escultor, obrante en la iglesia vallisoletana de San Ildefonso ${ }^{6}$, y el segundo a partir de la carta en la que su esposa María Pérez († 1663) dispuso sus últimas voluntades ${ }^{7}$. El hallazgo de nuevos datos sobre este particular, localizados en el Archivo de la Catedral de Plasencia, Sede para la que Fernández hizo uno de sus últimos y más importantes retablos, nos ha permitido plantearnos como objetivo para este trabajo aportar a su biografía la fecha concreta en la que rubricó su testamento, y reconstruir en parte su contenido, que hemos conocido parcialmente

1 Ayala Mallory, 1986: 88.

2 URREA FERNÁNDEZ, 1999.

3 MARTín GonZÁleZ, 1980.

${ }^{4}$ Entre las monografías más importantes, cabe citar el capítulo que José Martí y Monsó le dedicó entre 1898 y 1901 (MARTí Y MonSÓ, 1898-1901: 392-413), así como los trabajos que elaboraron sobre el artista Ricardo DE ORUETA y Duarte (1920), Beatrice I. Gilman Proske (1926), Juan Agapito y Revilla (1929) -con el objetivo de catalogar el conjunto de su producción-, Esteban García Chico (1952), M. ${ }^{a}$ Elena Gómez Moreno (1953), Salvador Andrés ORDAX (1976), las aportaciones documentales del ya citado GARCía CHICO (1941), y un largo etcétera.

5 URREA FernándeZ, 1999: 15.

${ }^{6}$ CeÁn BermúdeZ, 1800: II, 265.

7 Martí y Monsó, 1898-1901: 408-409. 
por el traslado que existe del mismo en el ya citado Archivo catedralicio placentino. Dicho traslado estuvo sujeto a la obligación que tuvieron sus herederos de presentarlo ante el Cabildo para poder recibir lo que se le adeudaba al artista aún después de su muerte en concepto de pagos por el retablo mayor de la Sede; esta cuantía restaba de los 500 ducados que el escultor tuvo que dejar en depósito durante un año como garantía de la obra que había realizado.

Junto a ello, también es interesante señalar los nuevos datos que ofrecemos sobre las adiciones que realizó el Cabildo al contrato firmado con Fernández, y sus dos consecuentes escrituras de fianzas, que vinieron a sumarse a las dos que ya conocíamos a través de la historiografía artística -y que citamos a continuación-. Asimismo, los documentos consultados nos han permitido reconstruir con mayor precisión la etapa final del citado retablo, del que aún faltaban por entregar algunas esculturas un año después del fallecimiento del escultor.

Gracias a las Actas Capitulares de Plasencia y a la riqueza documental de este Archivo, conocemos con detalle el proceso constructivo del monumental retablo catedralicio. Parece ser que todo estaba dispuesto - para su contratación- a mediados de 1623, año en que el Cabildo iniciaba los trámites pertinentes y nombraba la comisión encargada de elegir las trazas, la cual dictaminó, en julio de 1624, adquirir el diseño presentado por el arquitecto mirobrigense Alonso de Balbás. Aunque en un principio el Cabildo también le encomendó la ejecución material de la obra, el contrato le fue rescindido ante la importante baja que los ensambladores vallisoletanos Juan y Cristóbal Velázquez presentaron en agosto de ese mismo año de 1624, comprometiéndose a hacer la obra por 4.000 ducados frente a los 6.500 inicialmente estipulados con Balbás. Es de imaginar, como ya se ha dicho en varias ocasiones, que el Cabildo no sólo se veía beneficiado por la rebaja en el precio, sino también por la oportunidad que advirtió de atraer el interés de Gregorio Fernández para que se hiciera cargo de las esculturas del conjunto, teniendo en cuenta que los Velázquez habían colaborado con él en diversas ocasiones ${ }^{8}$.

Los contactos con Fernández se iniciaron al año siguiente, personándose éste en Plasencia el 4 de mayo de 1625 para acordar el precio de la escultura y fijar las condiciones. La envergadura de la obra y su alto coste, 7.000 ducados, no solo hicieron necesario que el pintor Diego Valentín Díaz actuara -el 30 de junio de 1625- en calidad de garante de los fiadores que había presentado el escultor el 28 de junio de ese año ${ }^{9}$, sino también que el Cabildo hiciera una serie de adiciones al contrato que ya había firmado con Fernández. La nueva escritura se otorgó en Valladolid el 5 de agosto de 1625 ante el escribano Miguel Becerra ${ }^{10}$; en ella se dejaba constancia de la obligatoriedad de cumplir con los plazos estipulados, de emplear madera de nogal en las esculturas de la custodia y de dejar - una vez asentado el retablo- un depósito de 500 ducados -integrantes a la última tercia paga- durante un año en poder del Cabildo para asegurar de este modo el buen trabajo realizado. En esta ocasión, María Pérez, mujer del escultor, también salió como fiadora de todo lo otorgado hasta el momento, cumpliendo así lo dispuesto por el Cabildo Catedral $^{11}$. Asimismo, el 12 de agosto de 1625 Juan y Cristóbal Velázquez se obligaron a ser fiadores de Gregorio Fernández en la obra de escultura según las condiciones que había añadido

${ }^{8}$ Los pormenores sobre el proceso de contratación de la obra los dio a conocer el profesor MARTín GonZÁLEZ, 1975: 297-320; 1980: 132-144

${ }^{9}$ GARCía ChICO, 1941: 183-184, y 182-189, para toda la documentación sobre el retablo que nos ocupa. MARTín GONZÁLEZ, 1975: 304; 1980: 135-136.

${ }^{10}$ Escritura de fianzas de María Pérez a favor de Gregorio Fernández, 5 de agosto de 1625, Archivo de la Catedral de Plasencia (ACP), legajo 91, exp. 14. En este documento se recogen los añadidos al primer contrato que estipuló el Cabildo con Gregorio Fernández para la ejecución de la escultura del retablo de la Catedral de Plasencia el 4 de mayo de 1625; dichos añadidos figuran en la carta de fianzas otorgada por María Pérez, quien a su vez daba poder a Cristóbal Velázquez para que procediera a otorgar dichas fianzas. BenAvides CHECA, 1907: 250-251. Méndez HernáN, 2004: 458, y, en general, 444-478, donde ya se adelantaban algunos de los datos en los que ahora profundizamos.

11 ACP, legajo 91, exp. 14. 


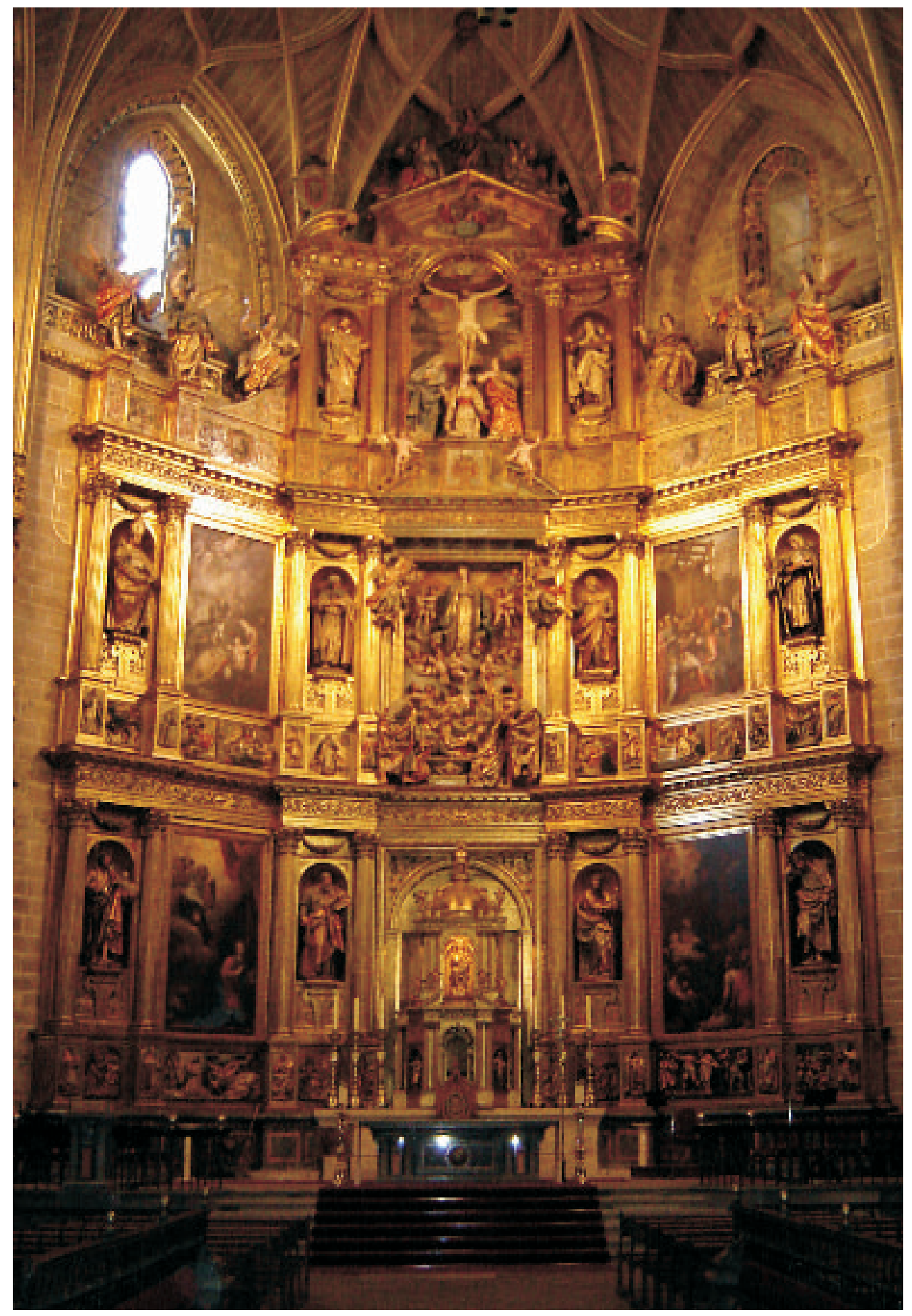

Fig. 1. Retablo mayor de la Catedral de Plasencia (Cáceres).

Arch. esp. arte, LXXXv, 339, JULIO-SEPTIEMBRE 2012, 265-292, ISSN: 0004-0428 
el Cabildo ${ }^{12}$-recordemos que Juan Velázquez había sido uno de los cuatro fiadores por los que Valentín Díaz tuvo de actuar como garante el 30 de junio de 1625-.

La acumulación de encargos en la última etapa del maestro y el desfallecimiento de sus energías, fueron las causas principales que motivaron el incumplimiento de los plazos en cuanto a la entrega de las piezas escultóricas. Pese a todo, el trabajo estaba prácticamente ultimado en la primavera de 1634; no se entiende de otro modo la tasación que hizo del conjunto el arquitecto mirobrigense Alonso de Balbás en abril de ese mismo año ${ }^{13}$. Es de imaginar que dicha tasación se entendió como el final de una obra en la que Fernández había estado trabajando -o al menos había tenido en su haber-, durante nueve años; y que a partir de esa fecha corría el año en el que el artista dejaba el depósito de los 500 ducados correspondientes a la tercera y última de las pagas acordadas de los 7.000 ducados ajustados. Los habituales retrasos de los comitentes a la hora de liquidar sus deudas, y el fallecimiento de Gregorio Fernández el 22 de enero de 1636, fueron los dos factores que motivaron el retraso del finiquito por el conjunto escultórico, que no se firmó hasta un año después de su muerte.

Según la nueva documentación localizada, el 1 de mayo de 1637 María Pérez, viuda del escultor, confesó haber recibido 1.835 reales que le entregó Bartolomé Mateo, ordinario de la ciudad, a cuenta de lo que aún se le adeudaba de la última paga del retablo mayor de la Catedral ${ }^{14}$. Poco después, el 26 de junio de aquel mismo año, se firmaba la carta de finiquito ante el escribano vallisoletano Manuel Monjes: María Pérez y su hija Damiana Fernández, que actuaba con poder de su cuarto marido -Juan Rodríguez Gavilanes, mercader de lencería-, otorgaron carta de pago en favor del Deán y Cabildo de Plasencia al recibir los 1.565 reales que les debían, resto del depósito acordado. De esta carta de pago conviene resaltar el siguiente texto, importante para ver las últimas piezas del retablo que no se entregaron hasta entonces:

“(...) y esta carta de pago otorgan sin perjuicio del dinero que tienen para cobrar la mitad de los portes de los quinientos ducados desta vltima paga y del derecho que tienen para pedir la echura de vn Dios Padre y una cena questá a la puerta de la custodia de la dicha yglesia, que yço el dicho Gregorio Fernández además de lo que tubo obligación azer $(\ldots) " 15$

Para que los herederos de Fernández pudieran hacer exequibles los pagos adeudados, tuvieron que aportar un traslado de la parte del testamento en la que sus herederos eran señalados como tales. La debilitada salud que tuvo el maestro en los últimos años de su vida, y las diversas ocasiones en las que fue desahuciado, debieron mover a Fernández a disponer sus últimas voluntades. Las referencias que conocíamos sobre este aspecto constan en la partida de defunción que publicó Ceán Bermúdez, según la cual Gregorio Fernández "hiço testamento y codicilo ante Miguel Becerra, escrivano de Su Majestad"; en él dispuso su enterramiento en la sepultura que poseía en el monasterio del Carmen Calzado, y por su ánima cien misas, la cuarta parte en esta parroquia, a la que además dejaba en limosna cincuenta reales para hacer la torre. Nombraba por testamentarios a su mujer María Pérez y al padre carmelita fray Juan López, prior de dicho convento ${ }^{16}$.

En virtud de la documentación que fue necesario trasladar a Plasencia, sabemos que el escultor y su mujer habían otorgado testamento el 11 de diciembre de 1633, y, como bien señaló Ceán

12 La escritura se otorgó ante el escribano placentino Jerónimo Navarro: ACP, legajo 91, exp. 14.

13 MÉndez HernÁn, 2004: 463.

14 ACP, legajo 91, exp. 14.

15 ACP, legajo 91, exp. 14. La imagen de la Última Cena debió desaparecer junto a las que en su momento recogió Martín GonZÁLeZ, 1975: 309. El Dios Padre, que corona el retablo, aún estaba sin terminar en octubre de 1630: GARCÍA CHICO, 1941:187.

16 CeÁn Bermúdez, 1800: II, 265. 
Bermúdez, lo hicieron ante el escribano vallisoletano Miguel Becerra. Ambos se nombraron testamentarios el uno del otro, junto a su yerno, el escultor zaragozano Juan Francisco de Iribarne -tercer marido de su hija Damiana-, y al canónigo Bartolomé de Rubrela. No obstante, la muerte del primero, ocurrida el 10 de noviembre de 1635, debió ser la causa para que, en última instancia, Fernández nombrara como tales a su mujer y al padre fray Juan López, prior del monasterio del Carmen Calzado; y debió hacerlo en su codicilo testamentario, del que Ceán Bermúdez nos aportó las noticias que conocemos sobre ese aspecto. Habida cuenta que este tipo documental -el codicilo- se podía otorgar cuando no implicaba un cambio de herederos, y que era el medio -como se recogía en el derecho romano- del que disponía el testador para introducir ligeras modificaciones en su testamento sin necesidad de otorgar uno nuevo, está plenamente justificado el traslado que hicieron su esposa y su hija de este protocolo a Plasencia, con el fin de constatar que eran las herederas del escultor.

El testamento localizado debió ser rubricado en el marco de la paralización que sufrió el asiento del retablo placentino entre los años 1632 y comienzos de 1634, a raíz de un retraso en la entrega de las esculturas, lo que a su vez debió estar motivado por un asunto de extrema gravedad, que induce a pensar en la nueva recaída que entonces sufriría Fernández y el consecuente desahucio por parte de los médicos. Tanto es así, que "estando enfermo", él y María Pérez decidieron otorgar testamento el 11 de diciembre de $1633^{17}$. La copia que de esta escritura se conserva tan solo es parcial ${ }^{18}$. Y como es frecuente en estos casos, comienza con las invocaciones a sus creencias en los Dogmas de Fe de la Iglesia Católica. Llama la atención el celo que pone Fernández en dejar bien asegurado el sustento de su esposa, cuyo cuidado encomienda a la hija de ambos y al tercer marido de ésta, el escultor zaragozano Juan Francisco de Iribarne († 1635), que entonces aún estaba con vida:

"Yten mando a la dicha María Pérez, mi querida y amada muger, el remanente del quinto de todos mis bienes, y le pido reciba mi buena voluntad que quisiera tener mucho que dejarla para que bibiera lo que le queda de vida con mucho descanso, y ruego y encargo mucho al dicho mi yerno e hija me miren mucho por ella con el cuidado que deuen a buenos y que yo tuviera con ellos y con sus cosas, así ayan mi bendición.”

En el traslado conservado del testamento también consta el nombramiento de su hija como heredera universal de sus bienes, y el de su yerno como uno de sus testamentarios junto al canónigo Bartolomé de Rubrela.

En un intento por reconstruir en parte el contenido del testamento, a estos datos habría que unir los que ya conocíamos a través del que María Pérez, viuda de Fernández, otorgó el 21 de abril de $1661^{19}$ dejando constancia de la manda que en su momento dispuso su marido y dotó de 150 reales destinados a una iglesia de Sarria, localidad natal del escultor ${ }^{20}$ situada en la actual provincia de Lugo, que no se había entregado y ordenaba abonar. Y habría que sumar también las referencias que conocíamos en virtud de la partida de defunción del artista, y a la que ya nos hemos referido: se mandó enterrar en el convento del Carmen Calzado, en la sepultura que era de su propiedad, y ordenó entregar 50 reales a la iglesia de San Ildefonso para "ayuda de hacer la torre"21. Entre los testigos del testamento se encontraba el escultor Mateo de Prado.

17 ACP, legajo 91, exp. 14. Ofrecemos una transcripción del testamento en el Apéndice Documental.

18 El traslado debió producirse pocos días antes de rubricar el finiquito del retablo mayor de la Catedral, lo que tuvo lugar en Valladolid el 26 de junio de 1637.

19 Martí y Monsó, 1898-1901: 408-409. Sobre este particular profundizaría Agapito y ReVILLA, 1945: 1-13, y 6 y 10-11, en lo que respecta al testamento de María Pérez.

20 Plaza Santiago, 1973: 505-509. VÁzquez Santos, R., 1999: 259-261; 2008: 47-52.

21 Cé́n BermúdeZ, 1800: II, 265. 


\section{APÉNDICE DOCUMENTAL}

Valladolid, 11 de diciembre de 1633

Testamento de Gregorio Fernández y su esposa María Pérez

ACP. Legajo 91, exp. 14. Traslado de la escritura original otorgada ante el escribano de Valladolid Miguel Becerra

"Yn dey nomine amen. Sea notorio a los que uieren esta pública escriptura de testamento y última disposición como nos Gregorio Fernandez, maestro escultor y arquitecto, y María Pérez, su muger, vezinos de esta ciudad de Valladolid, estando enfermo yo el dicho Gregorio Fernández e yo la dicha Maria Perez con salud y ambos en nuestro entero juicio y entendimiento natural, creyendo como firmemente creemos en el Misterio de la Santísima Trinidad, Padre, Hijo y Espíritu Santo, tres personas un solo Dios verdadero, y en todo lo demás que tiene, cree y confiesa la Santa Madre Yglesia de Roma y a gloria y onra de Christo Señor Nuestro y de la siempre Virgen María, su Bendita Madre, concebida sin pecado original, a quien ponemos por nuestra yntercesora y abogada con toda la corte del cielo, hacemos de conformidad nuestro testamento en la forma siguiente:

Yten mando a la dicha María Pérez, mi querida y amada muger, el remanente del quinto de todos mis bienes, y le pido reciba mi buena voluntad que quisiera tener mucho que dejarla para que bibiera lo que le queda de vida con mucho descanso, y ruego y encargo mucho al dicho mi yerno e hija me miren mucho por ella con el cuidado que deuen a buenos y que yo tuviera con ellos y con sus cosas, así ayan mi bendición.

Y para cumplir, pagar y ejecutar este nuestro testamento y cobrar y lo se deviere nos nombramos cada uno al otro por testamentarios y al señor canónigo Bertolomé de Rubrela y al dicho señor Juan Francisco nuestro yerno, a los quales y a cada uno dellos y cada uno al otro ynsolidum le damos y nos damos poder cumplido tan bastante como se requiere y es necesario para que por nuestra autorida de suya se entren e nos entremos en todos nuestros bienes y de lo mejor y más estimable dellos vendan los que bastaren en almoneda publica o fuera della y de su valor cunplamos y cunplan este nuestro testamento...

Y cunplido y pagado este nuestro testamento y todo lo en el dispuesto y ordenado, en el remanente de todos nuestros bienes muebles y rayzes, derechos y acciones, nombramos por nuestra ligitima y unibersal eredera en todos ellos a la dicha doña Damiana Fernandez, nuestra hija, la qual los aya y erede con la bendición de Dios y la nuestra. Y por esta escriptura revocamos y anulamos... (fórmulas) Lo qual lo otorgamos anbos a dos como dicho es ante el presente escrivano y testigos en la dicha ciudad de Valladolid, a onze dias del mes de diziembre del año de mile y seiscientos y treinta y tres, siedo testigos llamados y rogados Antonio Salvador y Marcos Garçía Sarmyento y Antonio de Rivera (sic) y Mateo de Prado y Joseph Bezerra, vecinos y estantes en la dicha ciudad, y los otorgantes a quien yo el dicho escrivano doy fee conozco. Lo firmó el dicho Gregorio Fernández, y por la dicha María Pérez, que dixo no saber firmar, firmó un testigo a su ruego. Gregorio Fernandez. Testigos Joseph Becerra. E yo el dicho Miguel Beçerra, escrivano y notario apostólico, público y real, vecino de Valladolid, fui presente. En testimonio de verdad, Miguel Becerra."

\section{BIBLIOGRAFÍA}

Agapito y Revilla, Juan, La obra de los maestros de la escultura vallisoletana. Papeletas razonadas para un catálogo, T. ${ }^{\circ}$ II, Fernández - Adiciones y correcciones, Valladolid, Casa Santarén, 1929.

Agapito y Revilla, Juan, "La Patria de Gregorio Fernández", en Boletín de la Real Academia de Bellas Artes de la Purísima Concepción, n. ${ }^{\circ}$ 17, Valladolid, 1945, pp. 1-13.

Andrés Ordax, Salvador, Gregorio Fernández en Álava, Vitoria, Excma. Diputación Foral de Álava, 1976. Ayala Mallory, Nina, Vidas, Madrid, Alianza Editorial, 1986.

Benavides Checa, José, Prelados placentinos. Notas para sus biografías y para la Historia Documental de la Santa Iglesia Catedral y Ciudad de Plasencia, Plasencia, Ed. del autor, 1907; de esta obra existe una reciente edición a cargo del Ayuntamiento de Plasencia, 1999.

Ceán Bermúdez, Juan Agustín, Diccionario de los más ilustres profesores de las Bellas Artes en España, Madrid, Imprenta de la Viuda de Ibarra 1800; Valencia, Ed. Facsímil de las Librerías París-Valencia, 1992. 
García Chico, Esteban, Documentos para el estudio del arte en Castilla. Tomo Segundo. Escultores, Valladolid, Publicaciones del Seminario de Arte y Arqueología de la Universidad de Valladolid, 1941.

García Chico, Esteban, Gregorio Fernández, Valladolid, Escuela de Artes y Oficios, 1952.

Gómez Moreno, M. ${ }^{a}$ Elena, Gregorio Fernández, Madrid, CSIC, 1953.

Martí y Monsó, José, Estudios Histórico-Artísticos relativos principalmente a Valladolid, Valladolid, Impr. de Leonardo Miñón, 1898-1901; Valladolid, Ed. Facsímil a cargo de Ámbito Ediciones y Diputación Provincial de Valladolid, 1992.

Martín González, Juan José, "El retablo mayor de la Catedral de Plasencia", en BSAA, T. ${ }^{\circ}$ XL-XLI, Valladolid, 1975, pp. 297-320.

Martín González, Juan José, El escultor Gregorio Fernández, Madrid, Ministerio de Cultura, 1980.

Méndez Hernán, Vicente, El retablo en la Diócesis de Plasencia. Siglos XVII-XVIII, Cáceres, Servicio de Publicaciones de la Universidad de Extremadura, 2004.

Orueta y Duarte, Ricardo de, Gregorio Hernández, Madrid, Saturnino Calleja, 1920.

Plaza Santiago, Francisco Javier de la, "El pueblo natal de Gregorio Fernández", en BSAA, T. ${ }^{\circ}$ XXXIX, Valladolid, 1973, pp. 505-509.

Proske, Beatrice I. Gilman, Gregorio Fernandez, New York, The Hispanic Society of America, 1926.

Urrea Fernández, Jesús (director científico), Gregorio Fernández. 1576-1636, cat. exp., Madrid, Fundación Santander Central Hispano, 1999.

Vázquez Santos, Rosa, “Gregorio Fernández, un entallador del siglo XVI. Nuevos datos sobre el origen y familia del escultor Gregorio Fernández”, en BSAA, T. ${ }^{\circ}$ LXV, Valladolid, 1999, pp. 259-261.

Vázquez Santos, Rosa, "Gregorio Fernández y Sarria: nuevas claves del taller familiar y su obra”, en Goya, n. ${ }^{\circ}$ 322, Madrid, 2008, pp. 47-52. 